\title{
RECUERDO DE RENATO TREVES
}

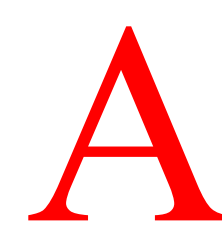

Elías Díaz y a mí nos fue encomendada la tarea de dictar las dos ponencias inaugurales del Congreso Internacional sobre Derecho, Sociedad y Libertad, en Milán el 13 de octubre de 1994, en memoria de Renato Treves. Me alegra mucho que el texto de mi discurso sea recogido ahora en el volumen de escritos en honor del amigo Elías, como testimonio de una larga y afectuosa amistad que nos ha unido a él, a Renato y a mí en un solo lazo. No puedo olvidar la deuda que nosotros, los dos viejos amigos turineses, tenemos con el más joven Elías por habernos iniciado en el conocimiento de la España libre durante el régimen de Franco.

Estamos aquí reunidos para recordar a Renato Treves, para muchos, los más jóvenes, un profesor que ha enseñado durante años en esta universidad; para muchos otros, un hombre de estudio que ha dedicado gran parte de la propia vida, con una pasión intelectual ininterrumpida, a la investigación en los distintos campos de la filosofía, de la sociología y del derecho, para otros un colega y un compañero de ideales; para mí, en fin, un amigo de toda la vida.

Renato, permitidme llamarlo con esta confianza, en su larga existencia (nacido en 1907, murió en 1993 a los ochenta y cinco años) atravesó, casi de principio a fin, este siglo ensangrentado -y que todavía sangra- por guerras terribles cuya violencia destructiva no tiene precedentes en la historia; trastornado por la gran ilusión de una revolución liberadora y por feroces reacciones contra ella; el siglo del final de los grandes imperios europeos y de la aparición por primera vez en la historia de campos de exterminio en los cuales fueron asesinados millones de sus hermanos. Lo atravesó bien consciente de esos horrores, pero sin perder la fe firme en que podía ser rescatado por los hombres libres y justos, que no deben ceder nunca a la tentación de abandonar el campo, no sólo celebrando verbalmente, 
sino practicando de hecho el principio de la tolerancia, sin traicionar nunca, ni siquiera en las horas más tempestuosas, la «misión del docto», como lo demuestra ejemplarmente la continuidad y la regularidad de sus escritos a lo largo de sesenta años, interrumpidos por el decenio del exilio argentino, serenamente, pues conoció, sí, el tormento de la duda interior, pero no se dejó paralizar por ella sino que, al contrario, encontró nuevos estímulos para corregirse y continuar caminando más allá.

Las obras académicas y de enseñanza que recubren los dos campos contiguos de la filosofía del derecho y de la sociología jurídica -el primero de los cuales desemboca poco a poco íntegramente en el otro-, se alternan con escritos de historia de la cultura, reflexiones sobre nuestro tiempo, testimonios y profesiones de fe. Unos y otros encuentran su culminación en la obra apasionadamente anhelada y largamente meditada, de la cual todos los escritos precedentes pueden ser considerados una larga preparación: el tratado de sociología del derecho. De él han aparecido varias ediciones: la primera en 1977, la segunda en 1980, la tercera, revisada y puesta al día en 1987 con el título cambiado del original Introduzione alla sociologia del diritto al nuevo de Sociologia del diritto, y el subtítulo de recapitulación Origini, ricerche, problemi, en 1988, después de seis reimpresiones y reaparecido en la Piccola Biblioteca Einaudi en el año 1993, el mismo año de su muerte ${ }^{1}$. Obra de conclusión porque es al mismo tiempo una obra de historia, de teoría, de investigación y -no por casualidad, sino intencionadamente, en la última parte dedicada al fin del derecho- de reflexión sobre la crisis de nuestro tiempo, en particular sobre la crisis del Estado social, y a la vez también una obra de perspectiva ideal.

A través de la lectura de autores que le eran queridos, entre los cuales sobresalen Hans Kelsen en el terreno más específico de la filosofía del derecho y Ortega en el terreno más amplio de la filosofía de la cultura, declara una vez más su confianza en el socialismo liberal, del cual ve como protagonista en Italia a Carlo Rosselli, y en España, su segunda patria, a Fernando de los Ríos. La obra, que es originalmente un texto de enseñanza y como tal ha sido utilizado durante todos estos años en muchas de nuestras universidades, termina con una llamada, traída de otro de sus autores, Theodor Geiger, a la función civil de los intelectuales.

${ }^{1}$ Nota del t.: En español el tratado de sociología del derecho ha sido editado en dos versiones: Introducción a la sociología del derecho. Traducción y nota preliminar de Manuel Atienza. Madrid: Taurus, 1978; y La sociología del derecho. Orígenes, investigaciones y problemas. Nota preliminar de Manuel Atienza: traducción de Manuel Atienza, María José Añón y Juan Antonio Pérez Lledó. Barcelona: Ariel, 1988. 
Las obras académicas a través de las cuales da comienzo su carrera universitaria, violenta e inicuamente truncada por las leyes raciales cuando estaba a punto de superar el concurso, pertenecen en gran parte a los primeros años. Las obras testimoniales y de compromiso militante pertenecen al segundo periodo, que se puede dar por comenzado a partir de la ruptura con el pasado provocada por el exilio forzoso. Él mismo recordó muchas veces la importancia que tuvo el exilio; importancia había tenido el decenio argentino, durante el cual enseñó sociología en la nueva universidad de Tucumán. Al menos por dos razones: ante todo, porque tuvo que preparar un nuevo campo de estudios que le proporcionó las bases culturales necesarias para dar el paso decisivo y definitivo de la filosofía del derecho a la sociología jurídica. Campo relativamente nuevo, porque el tema de su tesis de licenciatura [tesi di laurea] había sido la recepción del saintsimonismo en Italia, y Saint Simón reaparecerá en su obra culminante entre los fundadores de la sociología. Leo en la primera carta que recibí de él desde Tucumán, fechada el 22 de febrero de 1939: «Yo aquí, como te puedes imaginar, he tenido que volver a comenzar desde el principio», pero inmediatamente después añade: «Por suerte estoy dotado de una cierta testarudez que me podrá servir de ayuda». En segundo lugar, porque, liberado del clima culturalmente plúmbeo del régimen, en el cual toda manifestación libre del pensamiento era hostigada, se encontró de pronto en un mundo más libre, donde habían encontrado refugio no sólo exiliados italianos -baste recordar a Rodolfo Mondolfo, con el cual estrechó una devota y afectuosa amistad-, sino también ilustres exiliados de la guerra civil española. En este nuevo ambiente pudo abordar temas prohibidos en Italia, como la filosofía crociana de la libertad, el pensamiento político de Gobetti o la introducción a la traducción de la obra más conocida de Gioele Solari, nuestro común maestro, Filosofia del diritto privato. Nunca más fue obligado a reprimir las ideas que lo habían inspirado en los años de su formación turinesa a través de la amistad de jóvenes antifascistas, como Aldo Garosci -uno de los primeros de nuestra generación en exiliarse en París, donde se convirtió en uno de los colaboradores más estrechos de Carlo Rosselli- y de Umbero Segre, cuya obra y actividad evocó en 1979 en la introducción a la recopilación de sus escritos políticos, que apareció con el título de Verità e politica, verità della politica. En la introducción a la recopilación de escritos que tituló Libertà politica e verità (1962), habla con ardor, casi conmovido, de los encuentros en Argentina entre los emigrados por motivos raciales y los exiliados de la guerra civil de España. Entre otras cosas, escribe: «Nos acercaba una recíproca simpatía debida a la comunidad de ideas y de tendencias y el recuerdo de los vínculos que sobre el terreno práctico de la acción política habían 
unido a los italianos y a los españoles durante todo el siglo pasado, primero en la lucha por la libertad y la democracia, y después por la emancipación de la clase obrera.»

Nuestro muy querido maestro, Gioele Solari, había sido perentorio. El que pretendiera continuar sus estudios debía abrevar en las fuentes del pensamiento alemán. Por aquel entonces las nuevas corrientes de filosofía del derecho tras la crisis del positivismo eran bien neokantianas bien neohegelianas. Así fue como Renato y yo, junto a Ludovico Geymonat, nos encontramos en el verano de 1932 en Marburgo para asistir a un curso veraniego de alemán. Marburgo, por si alguien no lo supiera, daba el nombre a la corriente de filosofía neokantiana fundada por Hermann Cohen, considerado, con razón o sin ella, como uno de los inspiradores del jurista que era ya entonces, y aún iba a serlo todavía mucho más en los años sucesivos, uno de los protagonistas de la escena internacional de nuestros estudios: Hans Kelsen. Durante este mismo viaje a Alemania, Treves había hecho una escala en Colonia, donde Kelsen enseñaba antes de ser forzado a emigrar a Suiza tras la llegada de Hitler al poder. Este encuentro fue decisivo no sólo para la orientación de sus estudios, pues de él nació al año siguiente el amplio ensayo Il fondamento filosofico della dottrina pura del diritto -donde por «fundamento filosófico» entendía precisamente la filosofía de Cohen-, ensayo que puede ser considerado como el inicio del extraordinario éxito de la teoría pura del derecho en Italia, el inicio de lo que ha sido llamado el kelsenismo italiano; sino también porque el mismo Kelsen le confió la traducción de la primera síntesis de su teoría, que apareció en el mismo año en el Archivio Giuridico y precedía en un año a la primera exposición completa de la Reine Rechtslehre, que Treves mismo traduciría muchos años más tarde. Cuando Kelsen recibió la traducción le escribió una larga carta en la cual aclara sus presupuestos filosóficos: publicada sólo recientemente, debe considerarse como una fuente original para la interpretación auténtica del pensamiento kelseniano.

$\mathrm{Su}$ primer libro, recientemente reimprimido, nació en el año 1934 también como fruto del encuentro con Kelsen. El título era un poco sibilino: Il diritto come relazione. Sibilino, digo, porque no estaba claro desde el principio si el término «relación» se refería al derecho entendido en un sentido tradicional -y no habría sido ninguna novedad- como relación intersubjetiva y bilateral, o bien a la norma jurídica tal y como era entendida por Kelsen -y ésta sí era una solución original-, como relación entre un presupuesto (el acto ilícito) y una consecuencia jurídica (la sanción). En realidad, el último capítulo está dedicado a la teoría pura del derecho y al concepto de deber ser como característica de la relación normativa. No se le 
escape, sin embargo, al lector actual, a quien la discusión sobre la lógica universal del derecho a través de la cual el neokantismo reaccionaba frente al positivismo sin querer caer en el iusnaturalismo podría parecerle demasiado enrarecida, que al final de su investigación Treves mostraba su insatisfacción por el excesivo formalismo, que llevaba hacia un vaciado de contenido tal que desatendía, por considerarlos irrelevantes, muchos de los problemas más vitales de la ciencia jurídica hasta suscitar un «legítimo resentimiento entre los juristas». Era como decir que las corrientes formalistas merecían ser estudiadas como un punto de partida tras el positivismo, pero que no podían ser consideradas también un punto de llegada.

En efecto, con esta reflexión crítica puso las premisas para proseguir sus estudios más allá de las corrientes formalistas. En el prefacio al siguiente libro, que apareció en 1938, Il problema dell'esperienza giuridica e la filosofia dell'immanenza di G.Schuppe, recuperando el hilo interrumpido del estudio precedente y reafirmó que a través de la reducción del derecho a una mera relación Kelsen mutila su realidad y termina por provocar esa reacción antiformalista, de la cual se habían convertido en intérpretes los idealistas italianos, y descendiendo desde el cielo de la filosofía al mundo concreto de los hechos que han de ser indagados con un método científico, los sociólogos.

En un artículo poco conocido, reimprimido recientemente y en parte autobiográfico, «Dall' idealismo storicistico alla sociologia del diritto» (1957), explica qué distintas habían sido sus lecturas del ensayo de Max Ascoli sobre interpretación, primero cuando lo leyó en el momento de su publicación, en 1928, en los años en los cuales la filosofía dominante en Italia era todavía el idealismo historicista y, en un segundo momento, algunos años más tarde cuando en Argentina escribió el prefacio para su traducción al castellano. La primera lectura le había instruido sobre las posiciones antiformalistas que Ascoli combatía tomando como punto de referencia a las teorías elaboradas por los idealistas, en particular por el propio Croce, que sostenía la tesis de la naturaleza creadora de la interpretación jurídica. La segunda lectura, realizada después de que la enseñanza de la sociología le hubiera convencido de la necesidad de revisar la posición precedente y de «entender la experiencia jurídica esencialmente como una experiencia cultural que ha de ser estudiada y profundizada con los instrumentos de la sociología», le condujo a presentar el libro como un análisis de la experiencia jurídica «que traduce continuamente los hechos de la vida en normas». A través de este testimonio personal había querido demostrar que, contrariamente a una opinión enraizadísima entre los sociólogos, el interés por la sociología del derecho podía nacer del historicismo idealista: no obstante, 
esa derivación únicamente se refiere a la batalla común contra el formalismo, porque los idealistas no se plantearon el problema de convertir en operativos sus presupuestos teóricos, sino que se limitaron «a juguetear con las fórmulas mágicas de lo abstracto o de lo concreto» (juicio crítico que se refiere, por otro lado, al actualismo [el idealismo de Giovanni Gentile]).

El derecho «como experiencia cultural». La primera fase de su pensamiento, que continúa y profundiza la reacción contra el formalismo, se concluye con el libro Diritto $e$ cultura, aparecido primero en lengua española durante su estancia en Argentina, publicado también en Italia a su regreso, en $1947^{2}$. También este título requiere una breve explicación, pero para ello es preciso acudir a las corrientes filosóficas en las que Treves encontró la inspiración con la que colmar el vacío del análisis puramente formal del derecho, comenzando por Dilthey, quien contra la reducción de todas las ciencias en las ciencias naturales propias del positivismo, había devuelto el honor a la distinción entre ciencias de la naturaleza y ciencias del espíritu o de la cultura. En las últimas páginas Treves afirma que el derecho debe ser explicado a través de los elementos comunes que lo conectan a los otros fenómenos de la vida cultural, y añade que tal era la enseñanza aprendida del estudio de la sociología, en particular, de la sociología del conocimiento.

De ahora en adelante la consideración del derecho como experiencia cultural y el estudio de la sociología del derecho irán de la mano. En cierto sentido, la primera es el presupuesto filosófico de la segunda. Cualquiera que ojee los cursos de filosofía del derecho desarrollados en esta universidad desde 1948 en adelante, de los cuales han salido varias ediciones revisadas y ampliadas sucesivamente, se dará cuenta de que la filosofía de la cultura ocupa el lugar central del programa de enseñanza y de que desarrolla la función de marco teórico dentro del cual se sitúa el interés creciente por la sociología del derecho.

Desde entonces Treves se convierte en uno de los protagonistas del renacimiento de la sociología en Italia y, por lo que respecta a la sociología del derecho, en el pionero. Cuando en 1957 se funda la Associazione Italiana di Sociologia, es nombrado su presidente y desarrolla, en calidad de tal, la ponencia inaugural del primer Congreso Nacional de Sociología en el mismo año. Ya en 1948 había sido uno de los fundadores del Centro di Difesa e Prevenzione Sociale, en cuyas múltiples iniciativas participó en seguida activamente en colaboración amistosa con el secretario general, Beria

\footnotetext{
${ }^{2}$ Nota del t.: La versión en español, la primera en aparecer, fue la siguiente: Derecho y cultura. Buenos Aires: Editorial Depalma, 1947.
} 
d'Argentine. Dirige investigaciones y convenios de los que nacen varios volúmenes, como La sociologia nel contesto sociale (1959), y Giuristi e giudici nella società italiana (1972) ${ }^{3}$. Él mismo remite el nacimiento de la sociología del derecho a 1965, cuando la primera revista italiana de sociología, Quaderni di Sociologia, publica un número especial dedicado a esta disciplina con el que se proponía dar a conocer la obra de algunos miembros del Comité de Investigaciones Sociológico Jurídicas, fundado en Washington en 1962, que había nacido en el interior de la Asociación Internacional de Sociología. Hasta 1974, Treves fue el presidente de este comité.

Entre el nacimiento de la Associazione Italiana di Sociologia (1957) y la primera edición del tratado de sociología del derecho (1977) transcurren veinte años de contribuciones esenciales al desarrollo y a la difusión de esta disciplina en Italia. Me limito a recordar los dos volúmenes de escritos de varios autores sobre su estado en el mundo: $L a$ sociologia del diritto. Problemi e ricerche (1966) y el que le sucedió, Nuovi sviluppi della sociologia del diritto (1968). En el año 1974 funda la revista Sociologia del Diritto, que cumple hoy veinte años: punto de referencia y de irradiación de los estudios sociológicos en Italia, ha sido también un lugar de encuentro con los estudiosos y las investigaciones de otros países. En el primer número Treves tuvo la feliz idea de proponer algunas preguntas sobre la naturaleza y los fines de la disciplina: el vivaz debate que surgió de ahí entre juristas y sociólogos sobre los presupuestos teóricos de una actividad que precisa de la colaboración de unos y otros puede ser considerado como el bautismo de la disciplina.

A esta colaboración le ha proporcionado una contribución teórica fundamental su obra culminante, el ya mencionado tratado de sociología del derecho, cuyo desarrollo y perfeccionamiento se despliegan a lo largo de un decenio de replanteamientos, enriquecimientos y aclaraciones. El esquema teórico general sobre el que se construye la obra y sobre el que se distribuye la materia está basado en la distinción entre el estudio del derecho en la sociedad, que se propone reconocer cuál es el lugar que ocupa el derecho entre los fenómenos sociales -tema que tiene sus presupuestos, como ha quedado dicho, en la filosofía de la cultura- y el estudio de la sociedad en el derecho, que se ocupa de la realización de las normas, problema bien conocido por los juristas como la relación entre validez formal y eficacia. Conforme a esta distinción, la sociología del derecho presenta

${ }^{3}$ Nota del t.: hay traducción al español con el título de El juez y la sociedad. Una investigación sociológica sobre la administración de justicia en Italia. Escrito preliminar de Elías Díaz; traducción de Francisco Laporta y Ángel Zaragoza; revisada y anotada por Luis Mosquera. Madrid Edicusa, 1974. 
dos caras, ambas necesarias para comprender su compleja naturaleza: la cara que mira hacia el conocimiento de lo que precede a la producción de normas y la cara que mira hacia lo que la sucede. En otras palabras, el momento en el que el derecho como conjunto de reglas asciende desde la sociedad debe ser distinguido del momento en el cual desciende a la sociedad para regularla. La primera cara es aquélla cuyo conocimiento atañe a los sociólogos, la segunda es aquélla cuyo conocimiento atañe a los juristas. A través de la sociología del derecho, sociólogos y juristas son llamados a colaborar en una empresa común, que precisa de las competencias específicas de unos y otros. De este modo, la sociología del derecho se convierte en un lugar de encuentro obligado entre estudiosos de la sociedad y estudiosos del derecho.

La misma distinción entre la sociedad en el derecho y el derecho en la sociedad tiene una función discriminadora en la parte histórica de la obra, en la cual aparece diáfana la distinción entre la contribución aportada a la disciplina por los sociólogos, Comte, Spencer, Tönies, y la aportada por los juristas, Ehrilch, Gèny, Duguit, Pound. El entrecruzamiento de las dos perspectivas emerge todavía con mayor claridad en las obras de los autores que Treves considera los fundadores de la sociología del derecho: Max Weber, Georges Gurvitch, Theodor Geiger.

La obra termina con un último capítulo sobre el fin del derecho que constituye, junto con la parte histórica, la teórica, la metodológica y la informativa, una parte que no dudo en calificar de propositiva. Aparece de nuevo, casi como una conclusión, el ideal del socialismo liberal que procede filosóficamente desde el relativismo de Kelsen hasta el prospectivismo de Ortega.

El círculo se cierra. El final se abraza con el principio. Vuelven a aparecer los ideales de juventud nunca desmentidos, guardados entre unos pocos amigos en los años de formación turinesa y profesados públicamente durante el exilio argentino. De esta estancia merece ser recordado al menos el hermoso librito, no conocido porque no ha sido nunca traducido al italiano, sobre Benedetto Croce, filósofo de la libertad, aparecido en Buenos Aires en 1944. El propósito del libro era dar a conocer en la tierra del exilio, entre los prófugos del fascismo italiano y del franquismo, la existencia y la resistencia en la propia patria de una cultura no sometida. Además, desentierra un episodio mínimo que no hay que dejar caer en el olvido a propósito de las leyes raciales italianas, de las cuales habla desde la distancia del historiador. En 1938, año en el que fueron emanandas estas leyes, Croce había escrito en un breve inciso que en Alemania «todo se hincha como científico, y ahora es científico el racismo, es decir, una de las fabulaciones más pasionales y políticas que jamás hayan aparecido en el mundo». 
A pesar de la continuidad y la seriedad de su trabajo científico, nunca olvidó el compromiso civil. Además del volumen ya mencionado, Libertà politica e verità, publicó otras dos recopilaciones de ensayos, Spirito critico e spirito dogmatico, anterior a él (1954) y Sociologia e socialismo ${ }^{4}$, posterior, en los cuales recoge escritos sobre temas de cultura y de política y testimonios personales sobre sus maestros y amigos. Póstumo apareció el prefacio al libro de Paolo Bagnoli sobre el socialismo liberal, en el cual reafirmó, con la pasión de siempre y sin ocultar su nostalgia, sus antiguos ideales.

Renato era un perenne dubitativo, pero dirigía la duda crítica sobre todo hacia sí mismo. Tenía generalmente una confianza generosa en los demás. Nunca estaba satisfecho de sí mismo. Él también pertenecía al grupo, al que yo me honro en pertenecer, de los «eternos descontentos» [«mai contenti»]. Sus trabajos los hacía, los deshacía y los rehacía. A menudo me los enviaba antes de publicarlos y me preguntaba: «¿Qué te parece?». Al enviarme el escrito original de la introducción a la última redacción del tratado me escribe (24 de julio de 1987): «Revisando el libro para escribir esta introducción he advertido, como era previsible, muchos defectos: discutible la elección de los fundadores, insuficiente el análisis de muchas teorías». En una carta posterior (13 de diciembre de 1987), al enviarme una nueva redacción del mismo texto, se pregunta «si vale todavía la pena perder el tiempo con mi libro». Quién sabe si no tenía en mente a su Ortega, que se había preguntado: «¿Cómo va a luchar con otros el que vive en lucha consigo mismo? Los hombres que pelean con los demás son los fanáticos, es decir, los que están en paz consigo mismo. ¿Cómo va a tener humor de disputar con los demás el que a toda hora lo hace consigo mismo? Quien sabe que la íntima disputa es el ser auténtico del hombre no puede sentir un gran empeño en convencer a nadie de nada. [...] Es decir, los que no han pensado nada por sí son los que se afanan en convencer a los demás de muchas cosas $»^{5}$.

En las cartas del exilio, nunca un lamento, una recriminación, una invitación a ser compadecido. No hablaba de buena gana sobre la tragedia del pueblo hebreo. No recuerdo que hayamos hablado nunca sobre ello, a pesar de las muchas horas que hemos pasado juntos en nuestras casas, en los largos paseos por la montaña, en todos los congresos en los que nos tocó participar juntos. En un escrito

\footnotetext{
${ }^{4}$ Nota del t.: traducido al español por Luis C. Aparicio y Rafael de Asís: Sociología del Derecho y socialismo liberal. Madrid: Centro de Estudios Constitucionales, 1991.

${ }^{5}$ Nota del t.: José Ortega y Gasset: Revés de Almanaque, en Obras Completas. Madrid: Revista de Occidente, 1946 (2 $2^{\text {a }}$ edición, 1966), tomo II, p.737.
} 
autobiográfico, después de haber hablado del último libro publicado por él en Italia antes del exilio, escribe: «Pero el destino quiso bien pronto que tuviera que tomar contacto con otras corrientes del pensamiento filosófico-jurídico». Dijo «el destino». Él sabía bien y nosotros sabemos bien que lo que le arrancó de los amigos y de su viejo padre no fue un destino misterioso e inescrutable, sino la maldad de los hombres. Y como también nosotros lo sabemos y no lo hemos olvidado, no dejaremos que lo olviden quienes están destinados a sobrevivirnos.

(Traducción de Luis Rodríguez Abascal) 